\title{
Effect of in-season neuromuscular and proprioceptive training on postural stability in male youth basketball players
}

\author{
Lukáš Ondra*, Petr Nátěsta, Lucia Bizovská, Eliška Kuboňová, and Zdeněk Svoboda \\ Faculty of Physical Culture, Palacký University Olomouc, Olomouc, Czech Republic
}

Copyright: (C) 2017 L. Ondra et al. This is an open access article licensed under the Creative Commons Attribution License (http://creativecommons.org/licenses/by/4.0/).

\begin{abstract}
Background: Poor balance ability is a predictor of injuries of the lower extremity. Multi-intervention proprioception preventive programs, comprising balance training, strength, plyometric, agility, running, and stretching exercises, are effective in improving balance ability and reducing the risk of lower extremity injuries in athletes. Objective: The aim of the study was to examine the effect of a 20 -week in-season multi-intervention proprioceptive neuromuscular training program on postural stability in male youth basketball players. Methods: Twenty-one elite male youth basketball players were divided into an intervention group $(n=10$, age $17.3 \pm 1.3$ years $)$ and a control group $(n=11$, age $16.5 \pm 1.8$ years). During the in-season period ( 20 weeks), the intervention group followed a proprioceptive and neuromuscular training program, three times per week and 20 minutes per session. Balance was tested in a quiet unipedal stance (on both the dominant and non-dominant leg) on a foam mat with eyes open, before and after a 20-week period in both groups. The mean velocities in the medial-lateral and anterior-posterior directions and the mean total velocity of the centre of pressure (COP) displacement were obtained with a force platform. Results: The combined effect (pre-post test $\times$ group) showed that intervention resulted in significant improvement in the mean COP velocity for both the dominant and non-dominant limb in the anterior-posterior direction ( $p=.013$ and $p<.001$, respectively) and in the medial-lateral direction ( $p=.007$ and $p<.001$, respectively) as well as in the total COP velocity $(p=.009$ and $p<.001$, respectively). Conclusions: The specific proprioceptive and neuromuscular training had a positive effect on postural stability for both the dominant and non-dominant limb in basketball players.
\end{abstract}

Keywords: balance, centre of pressure, exercise

\section{Introduction}

Balance is controlled by neuromuscular responses, central processing and sensory input from peripheral receptors, which (i.e. sensory input) is obtained from the vestibular, visual and proprioceptive systems (Proske \& Gandevia, 2012). Balance exercises are often implemented as a part of neuromuscular and proprioceptive athletic training, which is understood as combination of balance, strength, plyometric, agility and sport-specific exercises (Mandelbaum et al., 2005; Zech et al., 2010). Each training program should conform to the particular level of sensorimotor processes according to specific sport discipline to perform skills and protect the neuromuscular system from injury (Bressel, Yonker, Kras, \& Heath, 2007).

\footnotetext{
* Address for correspondence: Lukáš Ondra, Department of Natural Sciences in Kinanthropology, Faculty of Physical Culture, Palacký University Olomouc, třída Míru 117, 77111 Olomouc, Czech Republic. E-mail: lukas.ondra01@upol.cz
}

Dynamic balance refers to maintaining equilibrium during motion (Davlin, 2004) and it is dependent on the dynamic postural stability of the body, which is contingent on neuromuscular control of displacement of all contributing body segments during motion (Zazulak, Hewett, Reeves, Goldberg, \& Cholewicki, 2007). To maintain balance, it is required to have stability and strength in lumbopelvic region of the body, which provides a foundation for movement of the both, i.e. upper and lower extremities, to support loads and to protect the spinal cord and nerve roots (Panjabi, 1992). The term "core" has been used to label the lumbopelvic region of the body (Reed, Ford, Myer, \& Hewett, 2012; Shah \& Varghese, 2014). Previous research has shown that performance of core exercises improves balance ability and postural control of athletes (McLeod, Armstrong, Miller, \& Sauers, 2009; Romero-Franco, Martínez-Amat, Hita-Contreras, \& Martínez-López, 2014) and healthy young adults (Shah \& Varghese, 2014; Yaggie \& Campbell, 2006). 
There are studies, which applied a proprioceptive neuromuscular intervention training program in-season in various male and female youth athletes. These studies were primarily focused on reducing lower limb injuries. Studies, comprising comprehensive warm-up programs (Soligard et al., 2008; Steffen, Myklebust, Olsen, Holme, \& Bahr, 2008; Walden, Atroshi, Magnusson, Wagner, \& Hagglund, 2012) to improve strength, neuromuscular control, running, balance, landing technique, core stability, agility, etc., reported promising results, indicating that its intervention programs may reduce the incidence of knee and ankle injuries. Other studies, comprising the training program with using the Biodex stability system, mini trampoline, and balance board (Malliou, Gioftsidou, Pafis, Beneka, \& Godolias, 2004), ankle disk (Wedderkopp, Kaltoft, Lundgaard, Rosndahi, \& Froberg, 1999) or specific designed programs implemented as regular training session (Junge, Rösch, Peterson, Graf-Baumann, \& Dvorak, 2002; Malliou et al., 2004; McGuine \& Keene, 2006; Wedderkopp et al., 1999), reported reducing rate of ankle sprains in basketball and soccer players (McGuine \& Keene, 2006), improving proprioception ability (Malliou et al., 2004) and decreasing the number of traumatic and overuse lower limb injuries (Junge et al., 2002; Wedderkopp et al., 1999).

Poor balance ability in both unilateral and bilateral stance is predictor of ankle sprain (McGuine, Greene, Best, \& Leverson, 2000; Trojian \& McKeag, 2006) and the other lower extremity injuries (Holden, Boreham, Doherty, Wang, \& Delahunt, 2014) in basketball players (McGuine et al., 2000; Wang, Chen, Shiang, Jan, \& Lin, 2006) and the other athletes (Guillou, Dupui, \& Golomer, 2007). Thus proprioceptive and neuromuscular intervention training effect, which is preventing the incidence of anterior cruciate ligament injuries (Hübscher et al., 2010; Mandelbaum et al., 2005) and ankle sprains (Eils, Schröter, Schröderr, Gerss, \& Rosenbaum, 2010; Hübscher et al., 2010), would be warranted. It was shown that multi-station or multi-intervention proprioception preventive programs comprising balance training, strength, plyometric, agility, running exercises, and stretching, are effective in reducing the risk of lower extremity injuries (Hübscher et al., 2010) in basketball players (Eils et al., 2010).

There are only few studies (Cumps, Verhagen, \& Meeusen, 2007; Emery, Rose, McAllister, \& Meeuwisse, 2007; Gaul, Fort-Vanmeerhaeght, RomeroRodriguez, \& Tesch, 2016; Longo et al., 2012), where the specific preventive training intervention programs for basketball players lasted for at least 20 weeks and where the training programs were performed during the season. The objective of this study was to examine the effect of 20-week multi-intervention proprioceptive neuromuscular training program in-season (from November to April) on postural stability in male youth basketball players. Based on the literature, it was hypothesized that multi-intervention proprioceptive neuromuscular training program would improve postural stability during unilateral tasks.

\section{Methods}

\section{Subjects}

A total of twenty-one male youth basketball players (age $16.9 \pm 1.6$ years, height $188.1 \pm 8.7 \mathrm{~cm}$, weight $77.9 \pm 10.6 \mathrm{~kg}$ ), recruited from basketball club BK Orli Prostějov, Czech Republic, volunteered to participate in this study. Exclusion criteria were chronic ankle instability and any lower extremity musculoskeletal injuries in the previous 6 months. The allocation of the participants was randomly assigned using permuted blocks of varying size. Criteria for randomisation to obtain homogenous groups included playing position and age. There were no significant differences between intervention and control groups in age, height, and weight (intervention group: $n=10$, age $17.3 \pm 1.3$ years, height $189.4 \pm 9.4 \mathrm{~cm}$, weight $77.9 \pm 7.8 \mathrm{~kg}$; control group: $n=11$, age $16.5 \pm 1.8$ years, height $187 \pm 8.2$ $\mathrm{cm}$, weight $77.8 \pm 13.1 \mathrm{~kg}$ ). The study was approved by the Ethics Committee (no. 3/2017) of Faculty of Physical Culture, Palacký University Olomouc, Czech Republic. Participants (or their parents in underage players) signed written informed consent before the start of the study.

\section{Balance testing}

Postural stability of each participant was tested before and after the 20 -week training period. The same investigators for both pre- and post- tests completed testing. Firstly, lower limb dominance was tested using three standard functional limb dominancy tests (step up, step after pushing of the body, and ball kick test). A limb was considered as dominant, if it scored at least in 2 out of 3 tests. Secondly, balance stability was tested using a force platform (Kistler 9286AA, Kistler Group, Winterthur, Switzerland, sampling rate 200 $\mathrm{Hz}$ ) with a balance pad (Airex balance pad, Airex AG, Sins, Switzerland) placed on the top of the platform. Each participant performed in total, three consecutive unilateral stances ( $30 \mathrm{sec}$ per trial) in eyes-opened conditions for each limb in alternating order (starting limb was randomly chosen by investigator) on force platform. All the participants were wearing shoes during the measuring. There was a rest period of $30 \mathrm{sec}$ between each trial. Before the start of every trial, each 
participant had a few seconds to stabilize the body. During the trial, a participant was watching the black square mark $(2 \times 2 \mathrm{~cm})$ in front of him in 2 meters distance. The centre of pressure (COP) coordinates were recorded to determine postural stability. The raw COP coordinates were low-pass filtered using a $4^{\text {th }}$ order Butterworth filter with a cut-off frequency of $10 \mathrm{~Hz}$. The mean velocities (mean of instantaneous velocities computed between each two consecutive COP positions) in the medial-lateral (ML) and anterior-posterior (AP) directions and the mean total velocity of the COP displacement were computed for both the dominant and non-dominant limbs of all subjects.

\section{Intervention training program}

The intervention period lasted for 20 weeks during an in-season period from November 2016 to April 2017. The multi-intervention proprioception preventive training program was developed by one of the investigators supervising the training sessions on the basis of his experience. Before every training session, there was a warm-up consisting of a whole body consecutive dynamic, strengthening, and stretching exercises performed as a part of the intervention program. There were two batteries of exercises, performed always in the same order, which included agility, balance, strength, and plyometric components (Table 1).

The first battery consisted of five isometric exercises, primary focused on knee flexors, hip extensors and abdominal muscles, and three dynamic exercises which followed right after three specific isometric exercises. Second battery was the whole body circuit training (2 rounds, $30 \mathrm{sec} /$ exercise) consisted of the combination of dynamic and static movements on 6 stations while using the following exercise equipment: Bosu (Ball-Dynaso bosa balance trainer - MAS4A111,
Master Sport, Ostrava, Czech Republic), Swiss ball (Swiss exercise ball, Theragear, Sumas, WA, USA), balance mat (Merco Balance Mat T33, York sport, Kroměřiž, Czech Republic), and kettlebell (inSPORTline Vin-Bel, SEVEN SPORT, Prague, Czech Republic). The training program consisted of three sessions a week.

Once a week, the intervention training program was placed before the standard training session and twice a week, it was performed as a part of the standard training session. The maximal duration of the intervention training program (i.e., both batteries, including warm up) was 20 minutes per session. The control group was performing a conventional warm-up with the other strength and conditioning coach during the whole intervention program.

\section{Statistical analyses}

Data from this investigation were analysed using STATISTICA (Version 10; Statsoft, Tulsa, OK, USA). The data were normally distributed, as investigated by the Kolmogorov-Smirnov test. For comparison of intervention and control groups an independent $t$-test was used. The repeated measure analysis of variance (ANOVA) was performed to test the combined effect of intervention program and group (intervention and control). Significance level was set at $\alpha=.05$. Effect size was assessed by partial eta squared $\left(\eta_{\mathrm{p}}^{2}\right)$ as follows: small effect $-\eta_{\mathrm{p}}^{2}=.2$, medium effect $-\eta_{\mathrm{p}}^{2}=.5$, large effect $\left.-\eta_{p}^{2}=.8\right)$.

\section{Results}

Before the training period we found no significant difference between intervention and control groups for

Table 1

Warm up and batteries of exercises

\begin{tabular}{|c|c|c|}
\hline Warm up & First battery of exercises & Second battery of exercises \\
\hline $\begin{array}{l}\text { Heel walking - } 10 \text { meters } \\
\text { Toe walking - } 10 \text { meters } \\
\text { Forward lunges with trunk } \\
\quad \text { rotation - } 12 \text { reps } \\
\text { Inchworm push up - } 6 \text { reps } \\
\text { Rollovers into V-sits - } 6 \text { reps } \\
\text { Spiderman lunges with vertical } \\
\text { rotation - } 8 \text { reps } \\
\text { Bent knee iron cross - } 12 \text { reps } \\
\text { Squat to stand - } 8 \text { reps } \\
\text { Straight leg raises - } 8 \text { reps each leg } \\
\text { Groiners - } 10 \text { reps } \\
\text { Leg swings front-to-back } \\
\quad \& \text { side-to-side }-10 \text { reps each leg } \\
\text { Jumping jack - } 10 \text { reps }\end{array}$ & $\begin{array}{l}\text { Isometric squat }-15 \mathrm{sec} \text { hold }+6 \text { squat jumps } \\
\text { Plank }-30 \mathrm{sec} \text { hold } \\
\text { Isometric forward lunge }- \text { hold } 15 \mathrm{sec}+6 \\
\text { reverse lung for each leg } \\
\text { Isometric push up }-10 \mathrm{sec} \text { hold }+6 \text { push up } \\
\text { Isometric single leg hip bridge }-15 \mathrm{sec} \text { hold } \\
\text { for each leg }\end{array}$ & $\begin{array}{l}\text { Isometric forward lunge (balance disc under } \\
\text { front foot) - } 15 \mathrm{sec} \text { hold for each leg } \\
\text { Straight arm plank on Swiss ball } \\
\text { Isometric squat on reversed Ball-Dynaso bosa } \\
\text { balance trainer } \\
\text { One leg deadlift using kettlebell in hand } \\
\text { Glute bridge with alternating front kicks } \\
\text { (legs on reversed Ball-Dynaso bosa balance } \\
\text { trainer) } \\
\text { Side to side jumps }\end{array}$ \\
\hline
\end{tabular}


both dominant (mean COP velocity in the ML direction: $t=0.706, p=.489$, mean COP velocity in the AP direction: $t=1.058, p=.303$, mean COP total velocity: $t=0.736, p=.471$ ) and non-dominant (mean COP velocity in the ML direction: $t=0.852, p=.405$, mean COP velocity in the AP direction: $t=1.206, p=.243$, mean COP total velocity: $t=0.783, p=.443$ ) limbs.

The intervention training program demonstrated positive effect in postural stability during unilateral stance for dominant and non-dominant limbs. Significant effect of group by time interaction was found in mean velocity in the ML direction for dominant $(p=.007$, $\left.\eta_{\mathrm{p}}^{2}=.327\right)$ and non-dominant $\left(p<.001, \eta_{\mathrm{p}}^{2}=.623\right)$ limbs (Table 2). There was also significant effect, in favour of the intervention group, in mean velocity in the AP direction for dominant $\left(p=.013, \eta_{\mathrm{p}}^{2}=.281\right)$ and nondominant $\left(p<.001, \eta_{\mathrm{p}}^{2}=.589\right)$ limbs similarly as for mean total velocity (dominant limb: $p=.009, \eta_{\mathrm{p}}^{2}=.312$, non-dominant limb: $\left.p<.001, \eta_{\mathrm{p}}^{2}=.649\right)$.

\section{Discussion}

The presented study evaluated the effectiveness of the multi-station proprioceptive exercise program for the ability to maintain balance, which might lead to the prevention of lower extremity injuries in the future. Integrating balance exercises into the warm-up (Bird \& Stuart, 2012; Pasanen, Parkkari, Pasanen, \& Kannus, 2009) and as a part of the training session (Ebben, Carroll, \& Simenz, 2004; Pau, Loi, \& Pezzotta, 2011) in various athletes is commonly used. The intervention training program, presented in our study, was successful in improving postural stability in both AP and ML direction for dominant and non-dominant limb of basketball players participating in the intervention group. Other results showed that the control group reported worse results of postural stability in both AP and ML direction for dominant and non-dominant limb in post testing compared to pre testing. Based on that fact, we concluded that postural stability of control group was decreasing during the seasons because of increasing load of muscular system and lack of exercises performed for compensation of those requirements. This can be considered as strong evidence that multi-intervention training programs should be placed as a regular training session during the season.

A study (Longo et al., 2012) presenting comparable training program with ours, consisting of three different

Table 2

Comparison of the results of basic COP velocity parameters of unilateral postural stability task for dominant and nondominant limb in control and intervention group

\begin{tabular}{|c|c|c|c|c|c|c|}
\hline & \multicolumn{2}{|c|}{ Pre } & \multicolumn{2}{|c|}{ Post } & \multicolumn{2}{|c|}{ Group by time interaction } \\
\hline & Mean & $S D$ & Mean & $S D$ & $p$ & $\eta_{p}^{2}$ \\
\hline \multicolumn{7}{|c|}{ Mean COP velocity in the medial-lateral direction $\left(\mathrm{cm} \cdot \mathrm{s}^{-1}\right)$} \\
\hline \multicolumn{7}{|l|}{ Dominant limb } \\
\hline Intervention group & 3.57 & 0.90 & 2.85 & 0.45 & .007 & .327 \\
\hline Control group & 3.36 & 0.45 & 3.68 & 0.55 & & \\
\hline \multicolumn{7}{|l|}{ Non-dominant limb } \\
\hline Intervention group & 3.54 & 0.72 & 2.67 & 0.39 & $<.001$ & .623 \\
\hline Control group & 3.29 & 0.59 & 3.84 & 0.64 & & \\
\hline \multicolumn{7}{|c|}{ Mean COP velocity in the anterior-posterior direction $\left(\mathrm{cm} \cdot \mathrm{s}^{-1}\right)$} \\
\hline \multicolumn{7}{|l|}{ Dominant limb } \\
\hline Intervention group & 3.51 & 0.85 & 2.81 & 0.34 & .013 & .281 \\
\hline Control group & 3.21 & 0.38 & 3.35 & 0.68 & & \\
\hline \multicolumn{7}{|l|}{ Non-dominant limb } \\
\hline Intervention group & 3.32 & 0.70 & 2.70 & 0.34 & $<.001$ & .589 \\
\hline Control group & 2.99 & 0.54 & 3.48 & 0.68 & & \\
\hline \multicolumn{7}{|c|}{ Mean COP total velocity $\left(\mathrm{cm} \cdot \mathrm{s}^{-1}\right)$} \\
\hline \multicolumn{7}{|l|}{ Dominant limb } \\
\hline Intervention group & 5.45 & 1.27 & 4.43 & 0.57 & .009 & .312 \\
\hline Control group & 5.15 & 0.53 & 5.54 & 0.95 & & \\
\hline \multicolumn{7}{|l|}{ Non-dominant limb } \\
\hline Intervention group & 5.24 & 1.00 & 4.20 & 0.50 & $<.001$ & .649 \\
\hline Control group & 4.93 & 0.79 & 5.75 & 0.99 & & \\
\hline
\end{tabular}


batteries of exercises combined with basketball specific movements, showed reduction in overall injury rate and lower extremity injuries. The intervention group had lower risk of trunk, leg, and hip and groin injuries as compared with the control group. If the high level of postural stability is considered as the factor reducing the risk of lower extremity injuries, there might be a connection with running or movement economy. This movement economy, which reducing the impairment of joints, is a cause of balanced/smooth stimulation of proprioceptors. We can consider that reduction in velocity in the ML and AP directions which was showed in our study can suggest improved coordination and also to attempt to reduce the incidence of any lower extremity injuries in the future.

Our neuromuscular proprioceptive training programme included a whole body consecutive dynamic, strengthening, stretching and isometric exercises with several variations mostly focused on knee flexors, hip extensors, and abdominal muscles, and it was designed to improve traditional training methods, including warm-up. A randomised controlled study (Pasanen et al., 2009) designed as a 6 months in-season neuromuscular programme for floorball players included sports-specific running technique, balance, jumping, and strengthening exercises improved player's sideways jumping speed and balance. These findings supported the importance of whole body multi-station intervention training program for improving lower extremity control.

Nevertheless, despite all the improvements in the studies, it still remains unclear, if the improved specific skills are transferable to the performance of competitive or recreational sport activities. Thus, proprioceptive preventive programs can be more likely effective in reducing sports-related lower extremity injuries. If there is any lower extremity musculoskeletal injury considered as one of the crucial factors affecting career of athletes, then health can be considered as the most important factor in improving performance in elite and non-elite athletes. Future studies should focus on evaluation of sport specific adaptation in technique, motor control, and overall performance.

There are some limitations in this study. First, sample size is relatively small compared to other studies, despite that fact, the number of players participating in our study is higher than the number of the full squad of any elite basketball team playing in the highest league in the Czech Republic. Second, there were no testing for training effects in strength (isokinetic etc.), power (vertical jump etc.) and agility (sideways speed, change in direction speed, etc.) which could be the factors influencing postural stability in athletic population.

The strengths of this study were as follows: Firstly, the intervention program was supervised by one of the investigators at all times, which reduced the potential errors in technique during performing specific exercises. Secondly, the intervention and control groups were similar in baseline characteristics and training and playing exposure during the intervention period. Thirdly, the intervention program was designed by one of the investigators specifically for the purpose of basketball training and its game characteristics and demands.

\section{Conclusions}

In summary, results showed that proprioceptive and neuromuscular training had a positive effect on postural stability for both dominant and non-dominant limbs in basketball players. Multistation proprioceptive preventive in-season training program can be recommended as a part of regular training session of youth basketball players.

\section{Acknowledgment}

This work was supported by a grant by Palacký University Olomouc (no. IGA_FTK_2017_011).

\section{Conflict of interest}

There were no conflicts of interest.

\section{References}

Bird, S. P., \& Stuart, W. (2012). Integrating balance and postural stability exercises into the functional warm-up for youth athletes. Strength and Conditioning Journal, 34, 73-79.

Bressel, E., Yonker, J. C., Kras, J., \& Heath, E. M. (2007). Comparison of static and dynamic balance in female collegiate soccer, basketball, and gymnastics athletes. Journal of Athletic Training, 42, 42-46.

Cumps, E., Verhagen, E., \& Meeusen, R. (2007). Efficacy of a sports specific balance training programme on the incidence of ankle sprains in basketball. Journal of Sports Science and Medicine, 6, 212-219.

Davlin, C. D. (2004). Dynamic balance in high level athletes. Perceptual and Motor Skills, 98, 1171-1176.

Ebben, W. P., Carroll, R. M., \& Simenz, C. J. (2004). Strength and conditioning practices of national hockey league strength and conditioning coaches. Journal of Strength and Conditioning Research, 18, 889-897.

Eils, E., Schröter, R., Schröderr, M., Gerss, J., \& Rosenbaum, D. (2010). Multistation proprioceptive exercise program prevents ankle injuries in basketball. Medicine and Science in Sports and Exercise, 42, 2098-2105. 
Emery, C. A., Rose, M. S., McAllister, J. R., \& Meeuwisse, W. H. (2007). A prevention strategy to reduce the incidence of injury in high school basketball: A cluster randomized controlled trial. Clinical Journal of Sports Medicine, 17, 17-24.

Gaul, G., Fort-Vanmeerhaeght, A., Romero-Rodriguez, D., \& Tesch, P. A. (2016). Effects of in-season inertial resistance training with eccentric overload in a sports population at risk for patellar tendinopathy. Journal of Strength and Conditioning Research, 30, 1834-1842.

Guillou, E., Dupui, P., \& Golomer, E. (2007). Dynamic balance sensory motor control and symmetrical or asymmetrical equilibrium training. Clinical Neurophysiology, 118, 317-324.

Holden, S., Boreham, C., Doherty, C., Wang, D., \& Delahunt, E. (2014). Dynamic postural stability in young adolescent male and female athletes. Pediatric Physical Therapy, 26, 447-452.

Hübscher, M., Zech, A., Pfeifer, K., Hänsel, F., Vogt, L., \& Banzer, W. (2010). Neuromuscular training for sports injury prevention: A systematic review. Medicine and Science in Sports and Exercise, 42, 413-421.

Junge, A., Rösch, D., Peterson, L., Graf-Baumann, T., \& Dvorak, J. (2002). Prevention of soccer injuries: A prospective intervention study in youth amateur players. American Journal of Sports Medicine, 30, 652-659.

Longo, U. G., Loppini, M., Berton, A., Marinozzi, A., Maffulli, N., \& Denaro, V. (2012). The FIFA 11+ program is effective in preventing injuries in elite male basketball players: A cluster randomized controlled trial. American Journal of Sports Medicine, 40, 996-1005.

Malliou, P., Gioftsidou, A., Pafis, G., Beneka, A., \& Godolias, G. (2004). Proprioceptive training (balance exercises) reduces lower extremity injuries in young soccer players. Journal of Back and Musculoskeletal Rehabilitation, 17, 101-104.

Mandelbaum, B. R., Silvers, H. J., Watanabe, D. S., Knarr, J. F., Thomas, S. D., Griffin, L. Y., ... Garrett, W., Jr. (2005). Effectiveness of a neuromuscular and proprioceptive training program in preventing the incidence of anterior cruciate ligament injuries in female athletes: 2-year follow up. American Journal of Sports Medicine, 33, 1003-1010.

McGuine, T. A., Greene, J. J., Best, T., \& Leverson, G. (2000). Balance as a predictor of ankle injuries in high school basketball players. Clinical Journal of Sport Medicine, 10, 239-244.

McGuine, T. A., \& Keene, J. S. (2006). The effect of a balance training program on the risk of ankle sprains in high school athletes. American Journal of Sports Medicine, 34, 1103-1111.

McLeod, T. C. V., Armstrong, T., Miller, M., \& Sauers, J. L. (2009). Balance improvements in female high school basketball players after a 6-week neuromuscular-training program. Journal of Sport Rehabilitation, 18, 465-481.

Panjabi, M. M. (1992). The stabilizing system of the spine. Part 2: Neutral zone and instability hypothesis. Journal of Spinal Disorders, 5, 390-397.

Pasanen, K., Parkkari, J., Pasanen, M., \& Kannus, P. (2009). Effect of a neuromuscular warm-up programme on muscle power, balance, speed and agility: A randomised controlled study. British Journal of Sports Medicine, 43, 1073-1078.
Pau, M., Loi, A., \& Pezzotta, M. C. (2011). Does sensorimotor training improve the static balance of young volleyball players? Sports Biomechanics, 11, 97-107.

Proske, U., \& Gandevia, S. C. (2012). The proprioceptive senses: Their roles in signaling body shape, body position and movement, and muscle force. Physiological Reviews, 92, 1651-1697.

Reed, C. A., Ford, K. R., Myer, G. D., \& Hewett, T. E. (2012). The effects of isolated and integrated "core stability" training on athletic performance measures. Sports Medicine, 42, 697-706.

Romero-Franco, N., Martínez-Amat, A., Hita-Contreras, F., \& Martínez-López, E. J. (2014). Short-term effects of a proprioceptive training session with unstable platforms on the monopodal stabilometry of athletes. Journal of Physical Therapy Science, 26, 45-51.

Shah, D. N., \& Varghese, A. (2014). Effect of core stability training on dynamic balance in healthy young adults - a randomized controlled trial. International Journal of Physiotherapy, 1, 187.

Soligard, T., Myklebust, G., Steffen, K., Holme, I., Silvers, H., Bizzini, M., ... Andersen, T. E. (2008). Comprehensive warm-up programme to prevent injuries in young female footballers: Cluster randomised controlled trial. BMJ, 337, a2469-a2469.

Steffen, K., Myklebust, G., Olsen, O. E., Holme, I., \& Bahr, R. (2008). Preventing injuries in female youth football - a cluster-randomized controlled trial. Scandinavian Journal of Medicine and Science in Sports, 18, 605-614.

Trojian, T. H., \& McKeag, D. B. (2006). Single leg balance test to identify risk of ankle sprains. British Journal of Sports Medicine, 40, 610-613.

Walden, M., Atroshi, I., Magnusson, H., Wagner, P., \& Hagglund, M. (2012). Prevention of acute knee injuries in adolescent female football players: Cluster randomised controlled trial. BMJ, 344, e3042-e3042.

Wang, H. K., Chen, C. H., Shiang, T. Y., Jan, M. H., \& Lin, K. H. (2006). Risk-factor analysis of high school basketball-player ankle injuries: A prospective controlled cohort study evaluating postural sway, ankle strength, and flexibility. Archives of Physical Medicine and Rehabilitation, 87, 821-825.

Wedderkopp, M., Kaltoft, B., Lundgaard, M., Rosndahi, K., \& Froberg, K. (1999). Prevention of injuries in young female players in European team handball: A prospective intervention study. Scandinavian Journal of Medicine and Science in Sports, 9, 41-47.

Yaggie, J. A., \& Campbell, B. M. (2006). Effects of balance training on selected skills. Journal of Strength and Conditioning Research, 20, 422-428.

Zazulak, B. T., Hewett, T. E., Reeves, N. P., Goldberg, B., \& Cholewicki, J. (2007). Deficits in neuromuscular control of the trunk predict knee injury risk: A prospective biomechanical-epidemiologic study. American Journal of Sports Medicine, 35, 1123-1130.

Zech, A., Hübscher, M., Vogt, L., Banzer, W., Hänsel, F., \& Pfeifer, K. (2010). Balance training for neuromuscular control and performance enhancement: A systematic review. Journal of Athletic Training, 45, 392-403. 